www.mdpi.com/journal/applsci

\title{
Communication
}

\section{Aqueous Microwave-Assisted Solid-Phase Synthesis Using Boc-Amino Acid Nanoparticles}

\author{
Keiko Hojo *, Natsuki Shinozaki, Yoshimi Nozawa, Yoshinobu Fukumori and Hideki Ichikawa \\ Faculty of Pharmaceutical Sciences \& Cooperative Research Center of Life Sciences, Kobe Gakuin \\ University, Chuo-ku, Kobe 650-8586, Japan; E-Mails: pjcdy075@s.kobegakuin.ac.jp (N.S.); \\ fukumori@pharm.kobegakuin.ac.jp (Y.F.); ichikawa@pharm.kobegakuin.ac.jp (H.I.)
}

* Author to whom correspondence should be addressed; E-Mail: hojo@pharm.kobegakuin.ac.jp; Tel./Fax: +81-78-974-40055.

Received: 13 May 2013; in revised form: 26 June 2013 / Accepted: 5 July 2013 /

Published: 24 July 2013

\begin{abstract}
We have previously developed water-based microwave (MW)-assisted peptide synthesis using Fmoc-amino acid nanopaticles. It is an organic solvent-free, environmentally friendly method for peptide synthesis. Here we describe water-based MW-assisted solid-phase synthesis using Boc-amino acid nanoparticles. The microwave irradiation allowed rapid solid-phase reaction of nanoparticle reactants on the resin in water. We also demonstrated the syntheses of Leu-enkephalin, Tyr-Gly-Gly-Phe-Leu-OH, and difficult sequence model peptide, Val-Ala-Val-Ala-Gly-OH, using our water-based MW-assisted protocol with Boc-amino acid nanoparticles.
\end{abstract}

Keywords: aqueous synthesis; solid-phase peptide synthesis; microwave assisted synthesis; nanoparticles; Boc chemistry

\section{Introduction}

The demands to develop green and sustainable synthetic methods in the field of fine chemicals, combined with regulatory pressure to produce these substances efficiently and safely, are increasing. The toxic and volatile nature of organic solvents poses a serious environmental threat [1]. Thus, the redesign of chemical processes to avoid hazardous organic solvents is highly desirable [2-4]. In recent years, there has been increased demand for the chemical synthesis of peptides for use in a wide variety of applications because of the explosive growth in biological research related to these molecules. 
However, chemical peptide syntheses consume extremely large quantities of organic solvent due to the multiple solvent-based condensation steps. Hence, there is a compelling need for new peptide synthesis technologies which do not damage the environment, and so there is increased focus on organic solvent-free methods of peptide synthesis using environmentally friendly solvents, such as water [5-11].

Water-based peptide synthesis remained unexplored for a long period, because the most common peptide building blocks, $t$-butyloxycarbonyl (Boc)- and 9-fluorenylmethoxycarbonyl (Fmoc)-amino acids $[12,13]$, are sparingly soluble in water. We recently reported aqueous peptide synthesis methods which utilize water-dispersible Boc- and Fmoc-amino acids nanoparticles [9-11]. This technology uses suspended nanoparticle reactants for the coupling reaction to overcome the solubility problem and offers many advantages in terms of reaction efficiency.

Figure 1. Aqueous microwave (MW)-assisted solid-phase synthesis using Boc-amino acid nanoparticles.

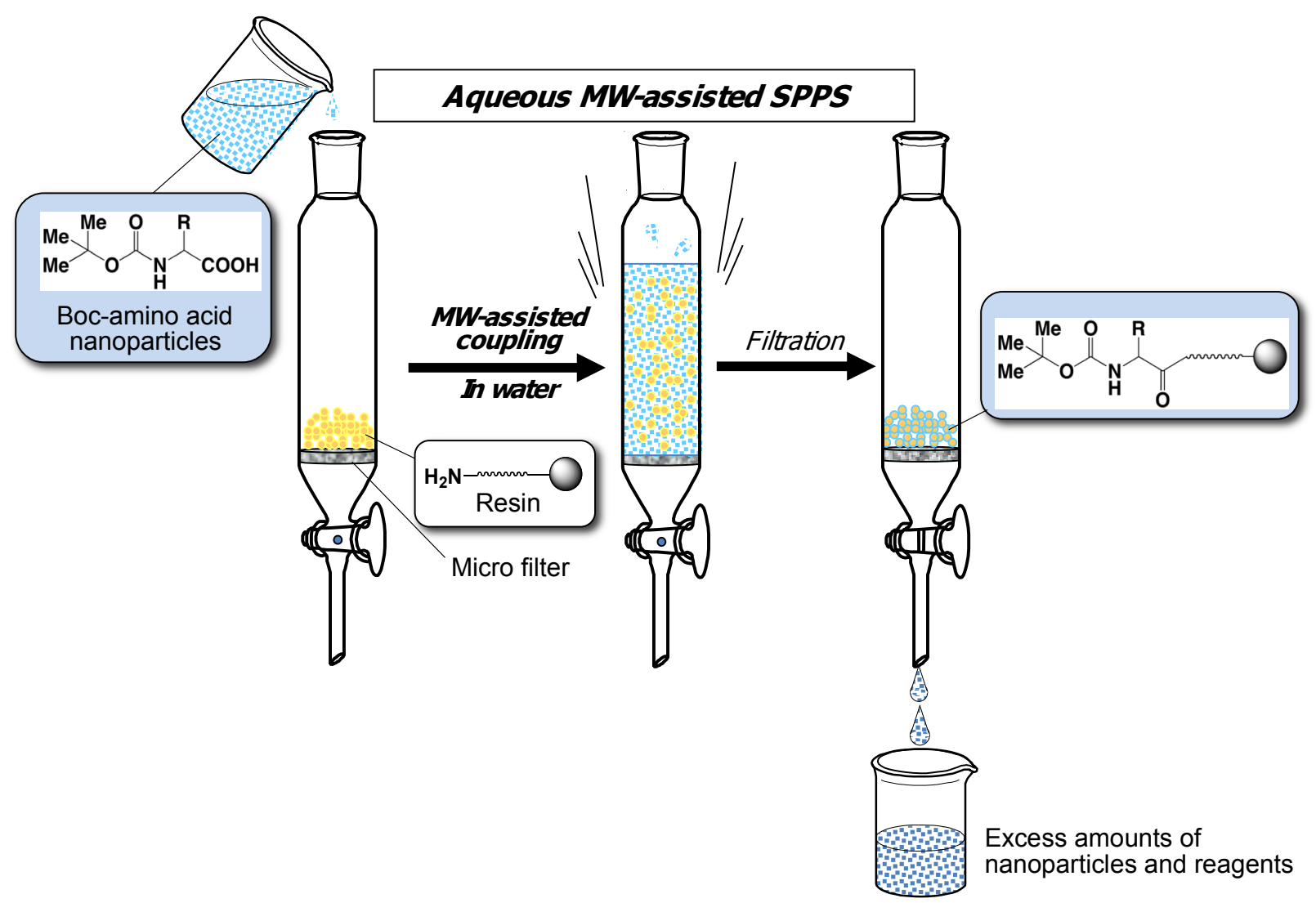

The use of non-conventional energy sources, viz. microwave (MW) irradiation has become a preferred choice for the organic chemist [1,14-16]. There are many examples of the application of MW irradiation in peptide synthesis, including automated peptide synthesizers equipped with MW capability [17-22]. The main advantages of MW-assisted chemistry are shorter reaction times and higher yields. These dramatic effects are caused by the unique heating profiles of MW irradiation. Unlike conventional heating, MW energy activates any molecule with a dipole moment, resulting in rapid heating. Indeed, the excellent dielectric properties of water offers significant advantages when used as a solvent in MW assisted reactions. The Boc strategy is well known to be suitable for industrial 
chemistry and green chemistry, because only gases are generated, without any other by-products produced by de-protection of the Boc group. Gases require less disposal energy than do solid wastes generated by de-protection of other protecting groups such as the Fmoc group. The trial of MW assisted water-based peptide synthesis using non-dispersed Boc-amino acids has been reported previously [23]. In this case, 2 reaction cycles were necessary to achieve complete coupling, requiring a total reaction time of over $15 \mathrm{~min}$. This reaction rate was slow compared to general peptide synthesis in ordinary organic solvents with MW irradiation. With this in mind, we present here a water-based solid-phase synthesis using water-dispersible Boc-amino acid nanoparticles in combination with microwave irradiation aimed at reducing reaction time and increasing reaction yield (Figure 1).

\section{Experimental Section}

Boc-amino acids were purchased from Watanabe Chemical Industries, Ltd. A planetary ball mill, model pulverisette 7 (Fritsch GmbH, Idar-Oberstein, Germany) was used for pulverization to prepare water-dispersible nanoparticles. The particle size of pulverized Boc-amino acids was determined by a dynamic light scattering (DLS) analysis, model LB-500 (Horiba Instruments Inc.). The MW-assisted reaction system used in this study was the $\mu$ Reactor Ex $(2.45 \mathrm{GHz})$ (Shikoku Instrumentation Co. Ltd., Takamatsu, Japan) equiped with an internal fiber-optic temperature sensor for power delivery contorol. MW reactions were performed in open polypropylene vessels. Reaction mixture was stired by a magnetic stirrer during the MW irradiation. Reversed phase HPLC was performed using a Waters model 600 instrument with a cosmosil $5 \mathrm{C}_{18}$-AR-II column and gradient system of acetonitrile/water containing $0.05 \%$ trifluoroacetic acid (TFA). Acid hydrolyses were performed in constant-boilng $\mathrm{HCl}$ at $110{ }^{\circ} \mathrm{C}$ for $24 \mathrm{~h}$ in evacuated tubes. Amino acid compositions of acid hydrolysates were determined with a Water Pico Tag amino acid analyzer. Mass spectra were measured with a Bruker micrOTOF-Q II instrument using the time of flight (TOF) technique.

\subsection{Preparation of Water-Dispersible Boc-Amino Acid Nanoparticles}

Boc-Phe-OH nanoparticles: An aqueous dispersion of nanoparticulate Boc-Phe-OH was prepared by grinding using a planetary ball mill. A $40 \mathrm{~mL}$ agate jar was charged with $0.5 \mathrm{~mm}$ diameter pre-cleaned zirconium oxide beads $(80 \mathrm{~g})$, Boc-Phe-OH $(531 \mathrm{mg}, 2.0 \mathrm{mmol})$, polyethylene glycol (PEG) (average MW $4000 \mathrm{~g} / \mathrm{mol}, 400 \mathrm{mg}, 0.1 \mathrm{mmol}$ ), and $25 \mathrm{~mL}$ of aqueous $0.2 \%$ Triton X-100 solution. The batch was rolled at $246 \mathrm{rpm}$ for $4 \mathrm{~h}$. After grinding, the beads were removed by filtration with $75 \mathrm{~mL}$ of aqueous $0.2 \%$ Triton X-100 solution. Particle size (mass mediam diameter): $327.3 \pm 14.1 \mathrm{~nm}$.

Boc-Leu-OH nanoparticles: particle size (mass mediam diameter) $=940.0 \pm 83.1 \mathrm{~nm}$.

Boc-Tyr (tBu)-OH nanoparticles: particle size (mass mediam diameter) $=281.5 \pm 2.7 \mathrm{~nm}$.

Boc-Tyr(BrZ)-OH nanoparticles: particle size (mass mediam diameter) $=394.2 \pm 10.1 \mathrm{~nm}$.

\subsection{Aqueous MW Assisted Coupling Reaction Study using Water-Soluble Coupling Reagents}

H-Gly-Rink amide-PEG grafted resin $(80 \mathrm{mg}, 20 \mu \mathrm{mol})$ was swollen with $0.2 \%$ Triton X-100 solution, then an aqueous dispersion of nanoparticulate Boc-Phe-OH $(5.0 \mathrm{~mL}, 100 \mu \mathrm{mol})$ was coupled onto the resin by water-soluble carbodiimide (WSCI, 1-ethyl-3-(3'-dimethylaminopropyl)carbodiimide 
hydrochloride) (19 mg, $100 \mu \mathrm{mol})$ or 4-(4,6-dimethoxy-1,3,5-triazin-2-yl)-4-methylmorpholinium chloride (DMTMM) (18 mg, $100 \mu \mathrm{mol})$. WSCI was used in conjugation with 3-sulfo- $N$ hydroxysuccinimide (sulfo-HOSu) $(22 \mathrm{mg}, 100 \mu \mathrm{mol}) . N, N$-diisopropylethylamine (DIEA) (17 $\mu \mathrm{L}$, $100 \mu \mathrm{mol})$ or 4-methylmorpholine (NMM) $(11 \mu \mathrm{L}, 100 \mu \mathrm{mol})$ were used for base catalysts. Each reaction mixture was heated at $70{ }^{\circ} \mathrm{C}$ by $\mathrm{MW}(<70 \mathrm{~W})$ irradiation and kept for 1-10 min. After MW irradiation, the resins were washed with $0.2 \%$ Triton $\mathrm{X}-100$ solution and ethanol. The coupling efficiency was checked by a Kaiser test. Results are summarized in Table 1.

Table 1. Study of MW assisted solid-phase coupling reaction in water [24]. Reactions were carried out between Boc-Phe-OH nanoparticles and H-Gly-Rink amide-PEG grafted resin.

\begin{tabular}{clccc}
\hline Entry & Reagent & Additive & Time/min & Kaiser test $^{a}$ \\
\hline 1 & WSCI & sulfo-HOSu & 10 & - \\
2 & WSCI & sulfo-HOSu & 3 & - \\
3 & WSCI & sulfo-HOSu & 1 & + \\
4 & DMTMM & - & 10 & - \\
5 & DMTMM & - & 3 & - \\
6 & DMTMM & - & 1 & - \\
\hline \multicolumn{5}{c}{ Kaiser test [25]. }
\end{tabular}

Preparation of H-Leu-HMBA-PEG grafted resin: HMBA-PEG grafted resin (181 mg, amino group content, $40 \mu \mathrm{mol}$ ) was swollen with $N, N^{\prime}$-dimethylformamide (DMF), the first amino acid, Boc-Leu-OH (46 mg, $200 \mu \mathrm{mol}$ ) was coupled onto the resin by $N, N^{\prime}$-diisopropylcarbodiimide (DIC) $(31 \mu \mathrm{L}, 200 \mu \mathrm{mol})$ and 4-(dimethylamino)pyrizine (DMAP) $(10 \mathrm{mg}, 80 \mu \mathrm{mol})$ in DMF. Boc deprotection was carried with TFA. The free amino group was neutralized with $0.5 \mathrm{~mol} / \mathrm{L} \mathrm{NaHCO}_{3}$ solution. The resulting resin was washed with $\mathrm{H}_{2} \mathrm{O}$ and $\mathrm{EtOH}$ and dried in vacuo. A minimum amount of resin was hydrolyzed with $0.5 \mathrm{~mol} / \mathrm{L} \mathrm{NaOH}$ solution, and the resulting mixture was filtered and neutralized $1 \mathrm{~mol} / \mathrm{L} \mathrm{HCl}$ solution. Then Leu content in hydrolysis solution was analyzed using Pico Tag amino acid analyzer. The Leu loading content of the resin was calculated from the amino acid analysis. Leu loading content, $21.5 \mu \mathrm{mol} / \mathrm{g}$. The resin was washed with $\mathrm{H}_{2} \mathrm{O}$ and used in the following synthesis.

\subsection{General Procedure for Aqueous MW Assisted Solid-Phase Peptide Synthesis}

Leu-enkephalin as an example: The solid-phase synthesis was carried out according to the protocol shown in Table 2. The H-Leu-HMBA-PEG grafted resin $(40 \mu \mathrm{mol})$ was swelled with $0.2 \%$ Triton $\mathrm{X}-100$ solution, then water-dispersible Boc-Phe-OH nanoparticles $(200 \mu \mathrm{mol})$, Boc-Gly-OH in $0.2 \%$ Trioton X solution $(200 \mu \mathrm{mol})$, and water-dispersible $\operatorname{Boc}-\mathrm{Tyr}(t \mathrm{Bu})-\mathrm{OH}$ nanoparticles $(200 \mu \mathrm{mol})$ were serially coupled onto the resin. Aqueous MW coupling reaction was performed by DMTMM (35 mg, $200 \mu \mathrm{mol})$, and NMM $(22 \mu \mathrm{L}, 200 \mu \mathrm{mol})$ at $70^{\circ} \mathrm{C}$ using $\mathrm{MW}(<70 \mathrm{~W})$ for $3 \mathrm{~min}$. Deprotection was carried out with TFA. The free amino group was neutralized with $0.05 \mathrm{~mol} / \mathrm{L} \mathrm{NaHCO}_{3}$ solution, followed by washing with $\mathrm{H}_{2} \mathrm{O}$. After completion of the synthetic reaction, the peptide resin (H-Tyr-Gly-Gly-Phe-Leu-HMBA PEG grafted resin) was washed with ethanol and dried in vacuo. The resin was treated with $3 \mathrm{~mL}$ of $0.5 \mathrm{~mol} / \mathrm{L} \mathrm{NaOH}$ solution for $30 \mathrm{~min}$ at room temperature. The resin was removed by filtration and then $1.5 \mathrm{~mL}$ of $1.0 \mathrm{~mol} / \mathrm{L} \mathrm{HCl}$ solution was added to filtrates in order to 
neutralized the base solution. The filtarte solution was lyophilized. The crude product was purified by preparative HPLC to give an amorphous powder. Yield (calculated from the amino group content of the used resin): $17.1 \mathrm{mg}$, 64\%; ESI-MS (TOF) $m / z$ : $556.2790\left(\mathrm{C}_{28} \mathrm{H}_{38} \mathrm{~N}_{5} \mathrm{O}_{7}\right.$ requires with calculated $[\mathrm{M}+\mathrm{H}]^{+}$556.6306); Amino acid rations in an acid hydrolysate: Tyr 0.94, Gly 2.02, Phe 1.00, Leu 0.97 (average recovery 94\%).

Table 2. Protocol for solid-phase peptide synthesis using a MW assisted coupling reaction in water.

\begin{tabular}{lll}
\hline \multicolumn{1}{c}{ Step } & \multicolumn{1}{c}{ Reagents } & \multicolumn{1}{c}{ Time } \\
\hline Washing & Water & $3 \mathrm{~min} \times 10$ \\
Coupling reaction & Water-dispersible Boc-amino acids & \\
& (3 equivalent) DMTMM, NMM, MW; $70{ }^{\circ} \mathrm{C} ; 70 \mathrm{~W}$ & $3 \mathrm{~min}$ \\
Washing & $0.2 \%$ Triton X-100 solution & $3 \mathrm{~min} \times 5$ \\
Washing & EtOH & $3 \mathrm{~min} \times 3$ \\
Deprotection & TFA & $10 \mathrm{~min} \times 2$ \\
Washing & $0.5 \mathrm{~mol} / \mathrm{L} \mathrm{NaHCO}_{3}$ solution & $3 \mathrm{~min} \times 3$ \\
\hline
\end{tabular}

Val-Ala-Val-Ala-Gly-OH: Yield (calculated from the amino group content of the used resin): $14.2 \mathrm{mg}, 53 \%$; ESI-MS (TOF) $m / z$ : $416.2704\left(\mathrm{C}_{18} \mathrm{H}_{34} \mathrm{~N}_{5} \mathrm{O}_{6}\right.$ requires with calculated $\left.[\mathrm{M}+\mathrm{H}]^{+} 416.4925\right)$; Amino acid rations in an acid hydrolysate: Val 1.03, Ala 2.01, Gly 1.00 (average recovery 98\%).

\section{Results and Discussion}

First, we studied the coupling efficiency of the MW assisted solid-phase reaction between Boc-Phe-OH nanoparticles and H-Gly-Rink amide-PEG grafted resin [26,27] using several coupling methods. To perform aqueous based solid-phase synthesis, the solid support is required to swell in water. PEG grafted resin was reported to have a high swelling ability in both non-polar and polar solvents including water. Water-dispersible Boc-Phe-OH nanoparticles were produced by dispersion-based processes with wet milling [28-30]. Boc-Phe-OH was ground with zirconia beads in aqueous $0.2 \%$ Triton X-100 soultion using a planetary ball mill for $4 \mathrm{~h}$ at room temperature. The beads were removed by filtration to obtain water-dispersible Boc-Phe-OH nanoparticles. The dispersed nanoparticles were found by DLS analysis to have a mass mediam diameter of $327.3 \pm 14.1 \mathrm{~nm}$ (Figure 2). We also prepared several hydrophobic Boc-amino acid nanoparticles, Boc-Leu-OH, Boc-Tyr $(t \mathrm{Bu})-\mathrm{OH}$, as a nanoparticle formulation using the same wet milling process. In the case of Boc-Val-OH, the nano-based materials, which the oily substrates were dispersed in aqueous phase uniformly, were obtained after wet milling. In the Boc strategy, the hydrophobic Bzl type groups are generally the first choice for the side chain protection step. We also successfully prepared water-dispersible Boc-Tyr(BrZ)-OH, which has a hydrophobic BrZ side chain protecting group [11]. 
Figure 2. Wet-milling in planetary ball mill (a) Photo image of unprocessed Boc-Phe-OH; (b) Photo image of water-dispersible Boc-Phe-OH nanoparticles.
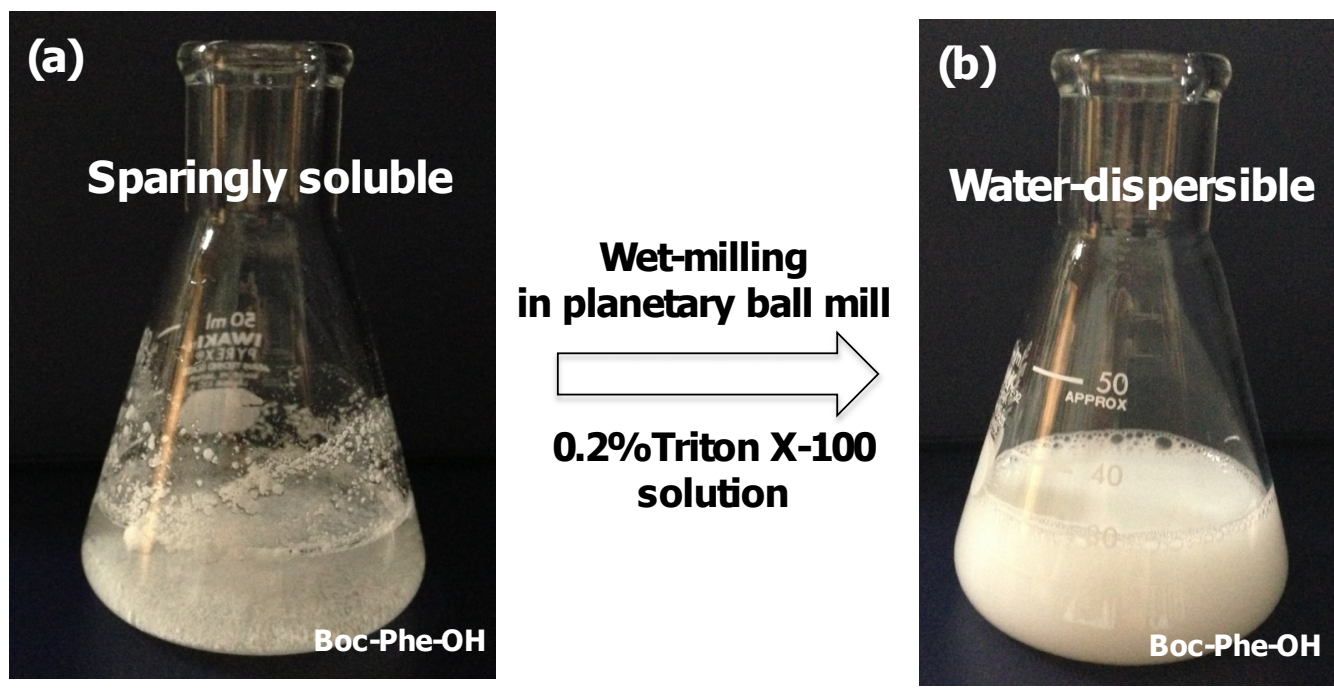

WSCI [31], DMTMM [32,33] and combinations of an additive sulfo-HOSu [34] were examined [24]. Reaction temperature was $70^{\circ} \mathrm{C}$ using a MW power of $70 \mathrm{~W}$ (Figure 1). The results are summarized in Table 1. The coupling reaction using WSCI in combination with sulfo-HOSu was completed within $3 \mathrm{~min}$ (Entry 2). Surprisingly, in the case of DMTMM (Entry 6), the reaction was completed in only $1 \mathrm{~min}$. In the previous work using Fmoc-amino acid nanoparticles, we have studied about efficiency of these aqueous MW-assisted coupling conditions. Even when using Fmoc amino acid nanoparticles, DMTMM showed a high reactivity in the aqueous reaction with MW irradiation [24]. These results were suggested that the microwave radiation in highly polar water-based solvent systems leads to very smooth reactions between aqueous nanoparticles and the solid support.

To evaluate the effectiveness of our procedure for MW assisted solid-phase synthesis in water using Boc chemistry, the preparation of the model peptide Leu-enkephalin (Tyr-Gly-Gly-Phe-Leu-OH, an endogenous opioid peptide) was investigated. The reaction was carried out in aqueous solution according to the protocol described in Table 2. The synthesis was carried out on an HMBA-PEG grafted resin, which is compatible with Boc chemistry [35]. The first amino acid, Boc-Leu-OH was introduced on the resin using DIC and DMAP in DMF. The water-dispersible Boc-Phe-OH and $\operatorname{Boc}-\operatorname{Tyr}(t \mathrm{Bu})-\mathrm{OH}$ nanoparticles were prepared by wet-milling in the presence of Triton X-100. Boc-Gly-OH was dissolved in aqueous $0.2 \%$ Triton X-100 solution. Boc-Phe-OH, Boc-Tyr $(t \mathrm{Bu})-\mathrm{OH}$ nanoparticles and Boc-Gly-OH solution were serially coupled onto H-Leu-HMBA-PEG grafted resin. Coupling reactions were carried out by DMTMM with MW radiation set to a power of $70 \mathrm{~W}$ for $3 \mathrm{~min}$ at $70{ }^{\circ} \mathrm{C}$. The Boc group was removed using TFA. After peptide synthesis on the resin, the Boc group and side-chain protecting group were removed by TFA. The objective peptide was cleaved from the resin with $0.5 \mathrm{~mol} / \mathrm{L} \mathrm{NaOH}$ solution. The HPLC analysis of the peptide obtained by solid-phase synthesis in water afforded a single peak for Leu-enkephalin, shown in Figure 3. The presence of only one peak in the chromatogram of the crude peptide suggested the absence of diastereomeric compounds. Thus, there is no significant racemization during the MW assisted coupling reaction. The overall yield calculated from the amino group content of the used resin was $64 \%$. 
Figure 3. (a) Analytical HPLC profile; and (b) mass spectra of Leu-enkephalin (YGGFL) obtained by MW assisted solid phase synthesis in water using nanoparticles. Elution was carried out for over $40 \mathrm{~min}$ at a flow rate of $1 \mathrm{~mL} / \mathrm{min}$ with a linear gradient from 9:1 to 5:5 mixture of $0.05 \%$ aqueous trifluoroacetic acid (TFA) and $0.05 \%$ TFA in acetonitrile. Column: 5C18-Ar-II $(2.4 \times 250 \mathrm{~mm})$.
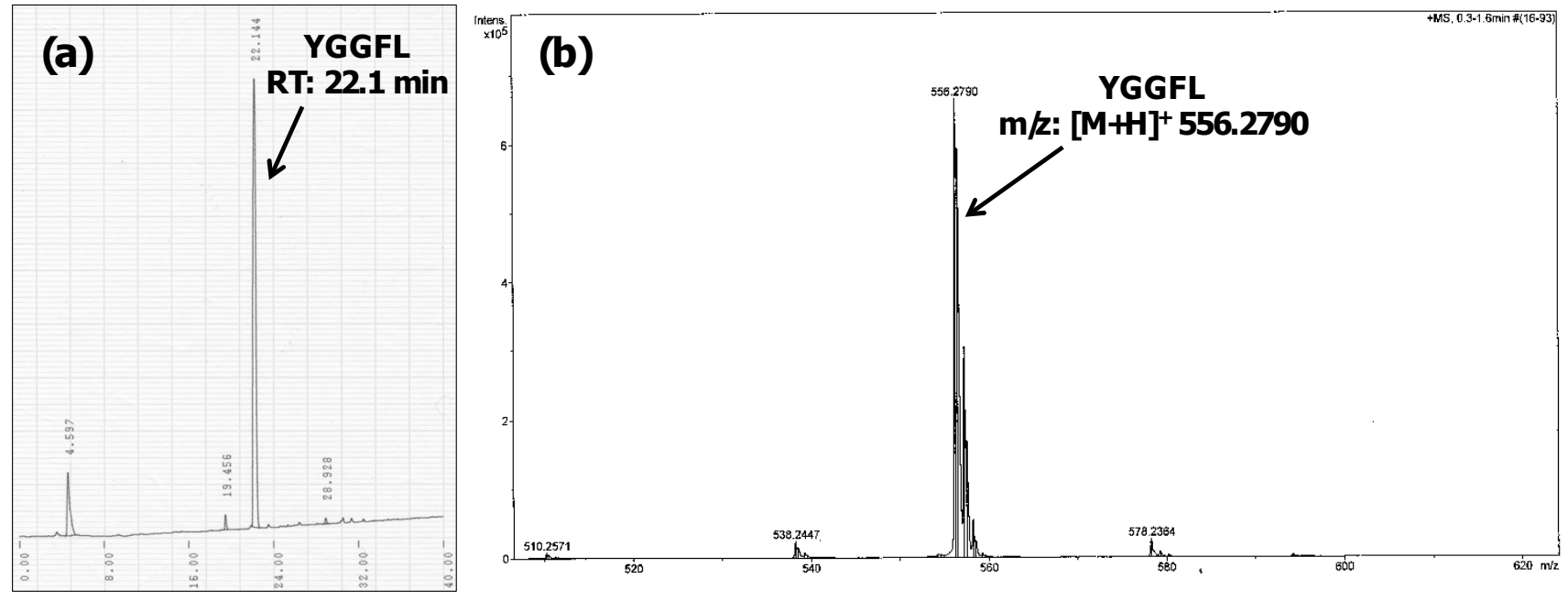

Figure 4. (a) Analytical HPLC profile; and (b) mass spectra of Val-Ala-Val-Ala-Gly-OH (VAVAG) obtained by MW assisted solid phase synthesis in water using nanoparticles. Elution was carried out for over $40 \mathrm{~min}$ at a flow rate of $1 \mathrm{~mL} / \mathrm{min}$ with a linear gradient from 95:5 to 55:45 mixture of $0.05 \%$ aqueous TFA and $0.05 \%$ TFA in acetonitrile. Column: 5C18-Ar-II $(2.4 \times 250 \mathrm{~mm})$.
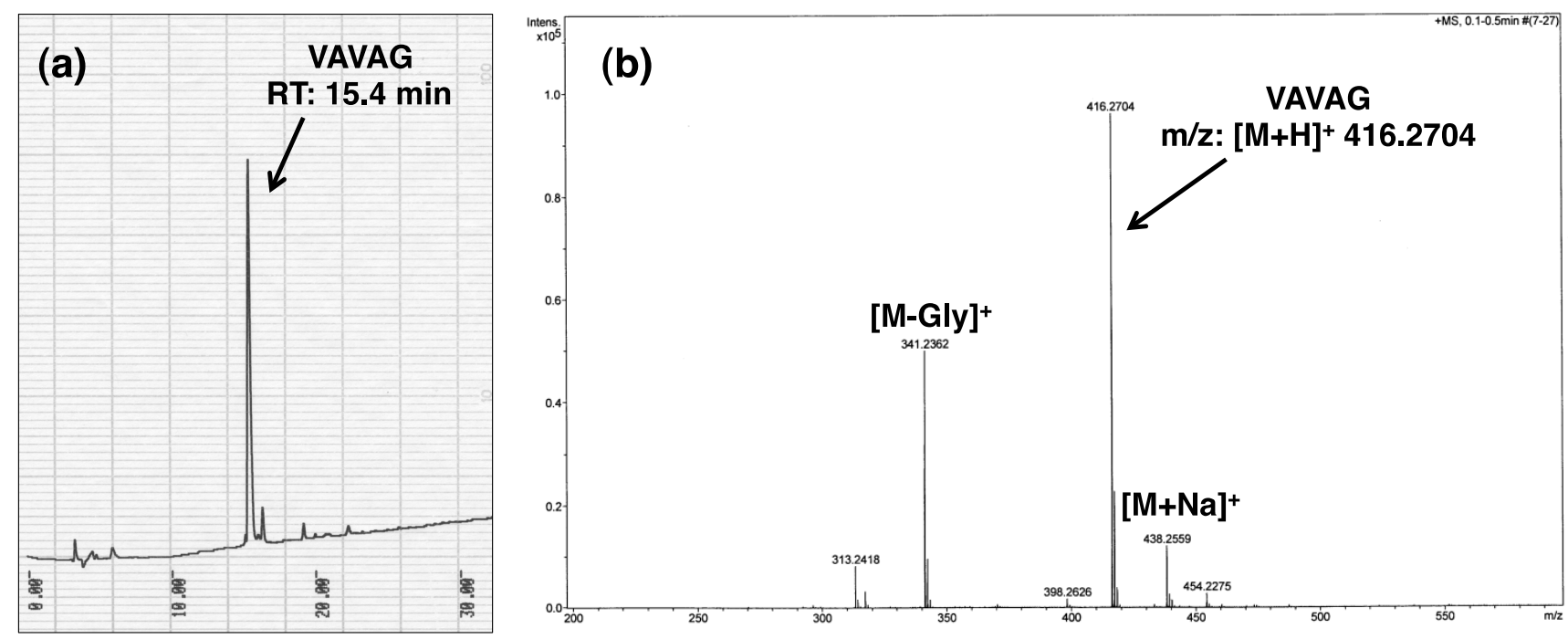

Difficult sequences peptides are problematic to synthesize using a conventional method due to the aggregation of protected peptide chain on the resin. MW irradiation is useful in breaking up the aggregation of a peptide chain. To further evaluate this aqueous MW-assisted synthesis method, we demonstrated the synthesis of hydrophobic peptide, Val-Ala-Val-Ala-Gly-OH, which is a well-known aggregate sequence [36]. Using a combination of MW irradiation and water-dispersible nanoparticles, 
we synthesized peptide on the HMBA-PEG grafted resin according to the same aqueous based protocol (Table 2). Boc-Val-OH nanoparticles and Boc-Ala-OH solution were serially coupled onto H-Gly-HMBA-PEG grafted resin. Figure 4 shows the HPLC analytical profile of Val-Ala-Val-AlaGly-OH synthesized in water by this method. The peptide was obtained in high purity.

\section{Conclusions}

In conclusion, the use of the MW irradiation allowed a rapid aqueous reaction of nanoparticle reactants on the resin. We have demonstrated that MW radiation can be successfully applied to the syntheses of Leu-enkephalin and a well-known aggregate peptide, Val-Ala-Val-Ala-Gly-OH, in high yield and purity. The most serious problems of aqueous based peptide synthesis are (i) the poor water solubility of protected amino acids; and (ii) slow reaction rates compared to general peptide synthesis in ordinary organic solvents. This approach, based on a combination of nanoparticle-based technology and MW heating, is emerging as a solution for these problems. Most solid-phase peptide syntheses are currently carried out in organic solvent using automatic synthesizer. This method using reactant nanoparticle suspension like reactant solution could be applied to automatic peptide synthesis, if more stable nanoparticle suspension would be prepared. Our method represents a major step forward in the development of effective and sustainable methods for solid-phase peptide synthesis.

\section{Acknowledgments}

This work was supported by a "Strategic Research Foundation" at Private Universities matching fund subsidy from the Japanese Ministry of Education, Culture, Sports Science and Technology, 2012-2016 (S1201010) and "Takeda Science Foundation".

\section{Conflict of Interest}

The authors declare no conflict of interest.

\section{References}

1. Polshettiwar, V.; Varma, R.S. Environmentally Benign Chemical Synthesis via Mechanochemical Mixing and Mirowave Irradiation. Eco-Friendly Synthesis of Fine Chemicals; Ballin, R., Ed.; RSC publishing: Cambridge, UK, 2009; pp. 275-292.

2. Anastas, P.T.; Warner, J.C. Green Chemistry: Theory and Practice; Oxford University Press: New York, NY, USA, 1998.

3. Winterton, N. Twelve more green chemistry principles. Green Chem. 2001, 3, G73-G75.

4. Sheldon, R.A. The E factor: Fifteen years on. Green Chem. 2007, 9, 1273-1283.

5. Hojo, K.; Maeda, M.; Kawasaki, K. A new water-soluble $N$-protecting group, 2-[phenyl(methyl)sulfonio]ethyloxycarbonyl tetrafluoroborate, and its application to solid phase peptide synthesis in water. J. Pept. Sci. 2001, 7, 615-618.

6. Hojo, K.; Maeda, M.; Kawasaki, K. A water-soluble $N$-protecting group, 2-[phenyl(methyl)sulfonio]ethoxycarbonyl tetrafluoroborate, and its application to peptide synthesis. Tetrahedron 2004, 60, 1875-1866. 
7. Hojo, K.; Maeda, M.; Kawasaki, K. 2-(4-Sulfophenyl)ethoxycarbonyl group: A new water-soluble $\mathrm{N}$-protecting group and its application to solid-phase peptide synthesis in water. Tetrahedron Lett. 2004, 45, 9293-9295.

8. Hojo, K.; Ichikawa, H.; Maeda, M.; Kida, S.; Fukumori, Y.; Kawasaki, K. Solid-phase peptide synthesis using nanoparticulate amino acids in water. J. Pept. Sci. 2007, 13, 493-497.

9. Hojo, K.; Ichikawa, H.; Fukumori, Y.; Kawasaki, K. Development of a method for solid-phase peptide synthesis in water. Int. J. Pept. Res. Ther. 2008, 14, 373-380.

10. Hojo, K.; Hara, A.; Kitai, H.; Onishi, M.; Ichikawa, H.; Fukumori, Y.; Kawasaki, K. Development of a method for environmentally friendly chemical peptide synthesis in water using water-dispersible amino acid nanoparticles. Chem. Cent. J. 2011, 5, 49.

11. Hojo, K.; Ichikawa, H.; Onishi, M.; Fukumori, Y.; Kawasaki, K. Peptide synthesis "in water" by a solution-phase method using water-dispersible nanoparticle Boc-amino acids. J. Pept. Sci. 2011, 17, 487-492.

12. McKay, F.C.; Albertson, W.F. New Amine-masking groups for peptide synthesis. J. Am. Chem. Soc. 1957, 79, 4686-4690.

13. Carpino, L.A.; Han, G. The 9-fluorenylmethoxycarbonyl function, a new base-sensitive. Amino-protecting group. J. Am. Chem. Soc. 1970, 92, 5748-5749.

14. Kappe, C.O.; Stadler, A. Microwaves in Organic and Medicinal Chemistry; Wiley-VCH: Weinheim, Germany, 2005.

15. Kappe, C.O. Controlled microwave heating in modern organic synthesis. Angew. Chem. Int. Ed. 2004, 43, 6250-6284.

16. Lidström, P.; Tierney, J.; Wathey, B.; Westman, J. Microwave assisted organic synthesis-A review. Tetrahedron 2001, 57, 9225-9283.

17. Olivos, H.J.; Alluri, P.G.; Reddy, M.M.; Salony, D.; Kodadek, T. Microwave-assisted solid-phase syntheisis of peptides. Org. Lett. 2002, 4, 4057-4059.

18. Erdélyi, M.; Gogoll, A. Rapid microwave-assisted solid-phase peptide synthesis. Synthesis 2002, $11,1592-1596$.

19. Yu, H.M.; Chen, S.T.; Wang, J.T. Enhanced coupling efficiency in solid-phase peptide synthesis by microwave irradiation. J. Org. Chem. 1992, 57, 4781-4784.

20. Collins, J.M.; Collins, M.J. Novel method for enhanced solid-phase peptide synthesis using microwave energy. Biopolymers 2003, 71, 361-366.

21. Murray, J.K.; Gellman, D.H. Application of microwave irradiation to the synthesis of 14-helical $\beta$-peptides. Org. Lett. 2005, 7, 1517-1520.

22. Bacsa, B.; Horvati, K.; Bosze, S.; Andreae, F.; Kappe, C.O. Solid-phase synthesis of difficult peptide sequences at elevated temperatures: A critical comparison of microwave and conventional heating technologies. J. Org. Chem. 2008, 73, 7532-7542.

23. Galanis, A.S.; Albericio, F.; Grøtli, M. Solid-phase peptide synthesis in water using microwave assisted heating. Org. Lett. 2009, 20, 4488-4491.

24. Hojo, K.; Ichikawa, H.; Hara, A.; Onishi, M.; Kawasaki, K.; Fukumori, Y. Aqueous microwave-assisted solid-phase peptide synthesis using Fmoc strategy: In-water synthesis of “difficult sequences". Protein Pept. Lett. 2012, 19, 1231-1236. 
25. Kaiser, E.; Colescott, R.L.; Bossinger, C.D.; Cook, P.I. Color test for detection of free terminal amino groups in the solid phase synthesis of peptides. Anal. Biochem. 1970, 34, 595-598.

26. Bayer, E. Towards the chemical synthesis of proteins. Angew. Chem. Int. Ed. 1991, 30, 113-129.

27. Rink, H. Solid-phase synthesis of protected peptide fragments using a trialkoxy-diphenyl-methylester resin. Tetrahedron Lett. 1987, 28, 3787-3790.

28. Rabinow, B.E. Nanosuspensions in drug delivery. Nat. Rev. Discov. 2004, 3, 785-795.

29. Liversidge, G.G.; Conzentino, P. Drug particle size reduction for decreasing gastric irritancy and enhancing absorption of naproxen in rats. Int. J. Pharm. Sci. 1995, 125, 309-313.

30. Liversidge, G.G.; Cundy, K.C. Particle size reduction for improvement of oral bioavailability of hydrophobic drugs: I. Absolute oral bioavailability of nanocrystalline danazol in beagle dogs. Int. J. Pharm. Sci. 1995, 125, 91-97.

31. Sheehan, J.C.; Hlavka, J.J. The use of water-soluble and basic carbodiimides in peptide synthesis. J. Org. Chem. 1956, 21, 439-441.

32. Kaminski, Z.J.; Paneth, P.; Rudzinski, J.A. Study on the activation of carboxylic acids by means of 2-chloro-4,6-dimethoxy-1,3,5-triazine and 2-chloro-4,6-diphenoxy-1.3.5-triazine. J. Org. Chem. 1998, 63, 4248-4225.

33. Kunishima, M.; Kawachi, C.; Morita, J.; Terao, K.; Iawasaki, F.; Tani, S. 4-(4,6-Dimethoxy1,3,5-triazin-2-yl)-4-methyl-morpholinium chloride: An efficient condensing agent leading to the formulation of amide and esters. Tetrahedron 1996, 55, 13159-13179.

34. Staros, J.V.; Wright, R.W.; Swingle, D.M. Enhancement by $N$-hydroxy-sulfosuccinimide of water-soluble carbodiimide-mediated coupling reactions. Anal. Biochem. 1986, 156, 220-222.

35. Sheppard, R.C.; Williams, B.J. Acid-labile resin linkage agent for use in solid phase peptide synthesis. Int. J. Pept. Protein Res. 1982, 20, 451-454.

36. Ajikumar, P.K.; Devaky, K.S. Solid phase synthesis of hydrophobic difficult sequence peptides on BDDMA-PS support. J. Pept. Sci. 2001, 7, 641-649.

(C) 2013 by the authors; licensee MDPI, Basel, Switzerland. This article is an open access article distributed under the terms and conditions of the Creative Commons Attribution license (http://creativecommons.org/licenses/by/3.0/). 